\title{
Aviation Management: A Discipline in Crisis?
}

\author{
Raymond A. Hamilton II, Wesley S. Randall, and Joe B. Hanna \\ Auburn University
}

\begin{abstract}
This article presents a detailed description of the key attributes of undergraduate aviation management programs. This exploratory research provides insight into key program issues in a manner designed to stimulate meaningful dialogue among aviation management faculty based on a study of 56 collegiate aviation baccalaureate programs. This investigation resulted in a taxonomy of aviation management curricula that examines: (1) breadth of curriculum, (2) science foundation, and (3) curriculum structure. Research results show that two primary dimensions emerged. The first is an operational vs. business processing oriented dimension. The second is a functional vs. asset understanding oriented curricula. The findings reveal that most programs are clustered around operational process-asset understanding. The authors advocate a need for increased business management oriented curricula focused by industry perspective and participation.
\end{abstract}

\section{INTRODUCTION}

Aviation programs and their faculty face a unique challenge. Representatives of aviation programs are charged with producing highly trained and educated students ready to make an immediate, positive impact on the aviation industry upon graduation. How to best accomplish this task is up for debate. Many feel it is imperative that the student possess all of the professional and operational skills and techniques that have traditionally been the focus of professional flight programs. While technical pilot capabilities remain important, industry increasingly expects faculty to prepare graduates for broader and more general business, management, and other non-flight related positions within a growing air transportation industry (Erickson, 2006).

The practitioner driven shift to a broad industry focus is good news for aviation faculty members who see "aviation" as an emerging discipline that is a core transportation mode in today's time-definite global transport oriented economy (Adrangi, Chow, \& Raffiee, 1997; Erickson, 2006; Taylor \& Jackson, 2000). This shift has generated increased demand for students who understand the nature of the global economy and the importance of transportation in servicing this type of economy (Golicic, Bobbitt, Frankel, \& Clinton, 2004). This shift has created advocates of aviation programs characterized by a managerially focused aviation curriculum model designed to prepare students for managerial roles in the aviation industry. These managerial roles are geared towards preparing students for emerging opportunities in the aviation industry. For example, the rapidly growing $\$ 40$ billion annual industry segment that is focused on after market service support to airlines provides students with high quality, management oriented jobs in the aviation industry. This industry segment has been created by entrepreneurs with business and managerial acumen who have in effect created a new industry segment by realizing there is greater profit potential selling things to the airlines than actually running an airline (Flint, 2007).

The apparent shift in skill sets required by industry practitioners has created debate among faculty in many aviation programs. How academic aviation programs handle the industry driven shift is uncertain, but likely to have a significant impact on the future of collegiate aviation programs and their students. As a result, aviation accreditation authorities, faculty, deans, and industry practitioners all appear to be considering the implications of a shift away from a technical training focused curriculum model toward a broader based educational initiative.

Some aviation faculty members argue a shift to a broader based educational curriculum model could dilute the operational content surrounding aviation as a profession (Phillips, Ruiz, \& Mehta, 2006). These faculty members 
tend to remain committed to a curriculum focused on the professional skills and techniques associated with the traditional professional pilot. Conversely, other aviation faculty members are embracing a new paradigm where the aviation industry is the backbone of a global timedefinite transportation economy requiring young professionals with managerial capabilities beyond the cockpit (Engler, 2007; Fabey, 2007). These faculty members believe in a curricula focused on educating students to have broad business based skills that prepare them for an eventual upper-level management position within the aviation industry.

It appears a challenge faces academic collegiate aviation programs as they attempt to respond to economic shifts and a growing divergence in paradigm views (Kavanagh, 1994; Kuhn, 1996; Meredith, Raturi, AmoakoGyampah, \& Kaplan, 1989). This article provides a method to better understand if this transition is causing a crisis in the aviation discipline and, if so, the nature or severity of the crisis. To more deeply analyze this, the investigation provides an aggregate level taxonomy of four-year collegiate aviation management curricula based on the content built into various curricula models and the relative weight of that content in various curricula. This analysis provides insight into the dominant orientation of aviation baccalaureate programs across 56 collegiate aviation programs. As a baccalaureate degree program each deals with some element of aviation. Some of the programs are broad based and oriented toward management of the aviation industry; others are more narrowly focused on the management of aviation technology or flight.

Understanding the dominant orientation of programs designed to educate future aviation related managers will assist decision makers tasked with performing academic program reviews as they prepare their programs, and their graduates, for success in the aviation industry of the future (Wergin, 2003). As with other disciplines (Burrell \& Morgan, 1979; Hunt, 1992) understanding the dominant orientation of

a discipline provides a foundation for meaningful dialogue to better understand emerging and divergent views of a discipline. To accomplish this, our investigation relies on exploratory content analysis (Randall \& Defee, 2008) to aggregate the US aviation curriculum and generate an understanding of the nature of the discipline's shift. Results of this methodology provide readers with information on where the curricula of aviation programs originated and where programs stand currently. Perhaps more importantly the results allow for meaningful dialogue and an insightful projection about the future of aviation programs and their curricula. The results of the analysis and projection should provide insight into logical questions such as how aviation curricula should be modified to meet the demands of industry.

\section{BACKGROUND AND LITERATURE REVIEW}

In their research on industry's view of the weaknesses of aviation management graduates, Phillips, Ruiz, and Mehta (2006) reported "The student's aviation knowledge is excellent. This is their greatest strength [however]. . . . graduates must also possess a much greater knowledge of the aviation industry and its business practices. Respondents of our research indicate that technical expertise alone does not ensure success in the aviation industry." The debate over how to prioritize content of an aviation curriculum model is nothing new to the field. From a pedagogical perspective a baccalaureate curriculum which best prepares graduates for success in the aviation industry should logically evolve along with the aviation industry (Quilty, 2004, p. 63). However, academicians and practitioners alike frequently differ on the direction of industry and how to effectively integrate industry evolution into the curricula models of various aviation programs. In his recent critique of aviation management programs, Phillips (2004) cited the difficulty in defining "aviation management" as a discipline, based on his analysis of 117 UAA member institutions, and he noted "flight and aviation management programs are linked much like conjoined-twins. The degree to which the programs are linked may put too much emphasis on the technical aspects of aviation at the expense of the management aspects." (p. 47).

Early on, the University Aviation Association (UAA) was recognized as the 
primary agency to ascertain the key areas of content and relative importance of content by which collegiate aviation management curriculum could best serve the industry (Fairbairn, 1987). Aviation educators, however, do not share a common understanding about the criteria to best evaluate aviation management programs, particularly as they face new industry dynamics (Clark, 2006; Phillips, 2004). For example, two studies conducted in 1989 and 1995 each surveyed airport managers on curriculum needed for an airport management career. These studies yielded little agreement when compared to UAA curriculum guidelines during the period of the studies (Kaps, 1995). Other articles highlighted competing views in the evolutionary and diverging nature of aviation management curricula. While many studies have a restricted focus on specific skill-based professional career tracks, such as airport management, air traffic control, etc., consensus has emerged on the substantive content, three categories seem to capture this content: (1) specific industry knowledge, (2) writing, speaking, and interpersonal communication, and (3) personal behavior related to work ethic and initiative (Phillips et al., 2006).

This evolution is not lost on the Aviation Accreditation Board International (AABI) the international accrediting agency for collegiate aviation programs. AABI has elected to base its future program accreditation evaluation criteria on measurable program outcomes. These measures focus on decision making capabilities, analytical capabilities, managerial acumen, and even communication skills. This is a sharp contrast to past accreditation criteria that have focused on the measurement of metrics such as curriculum contact hours, library facilities, technical skills, faculty credentials, and training methods.

The shift in focus of the accreditation criteria is considerable and is likely to undergo some scrutiny by member institutions seeking a definition of a common core aviation curriculum from which to benchmark their programs. Given this transition, an exploratory analysis is an important step as the academy properly prepares for, and responds to, the evolutionary processes confronting the discipline. A primary goal of our research is to aggregate and evaluate data from 56 collegiate aviation management programs to provide input into what categories and dimensions the "core" curriculum content is based and illustrate where the discipline is currently positioned.

Articulating and developing a common understanding can aid individual programs as they rationally determine their distinctive characteristics and determine their key differentiating qualities. Additionally, a common understanding of the current state of aviation management program curricula can also help to highlight areas that justify additional development or consideration. The investigation is oriented towards greater understanding of the following six research questions.

\section{RESEARCH QUESTIONS}

1. What are the substantive focus areas of the various collegiate 4 year aviation management curricula?

2. What is the intellectual objective of the various curricula?

3. What is the scope of knowledge the current curricula expects to impart to the student?

4. For what element or segments of the industry are these curricula preparing the graduates?

5. What elements or segments of the industry do aviation faculty members and their respective curricula intend to prepare graduates for today? In the future?

6. Is there a growing divergence in the conceptualization of the proper collegiate aviation curricula among academicians?

As aviation programs move forward reevaluating themselves in preparation for new AABI accreditation criteria, a logical self critique is necessary to understand the needs of students and industry. Does the compilation of the individual programs curricula based skills and knowledge intentionally, or unintentionally, define each program? Additionally, by aggregating the key content areas of all collegiate aviation programs, the results may provide a broad typology of skills that aviation educators have intentionally, or unintentionally, 
defined as meeting the demands of industry and students. The method employed proposes such aggregation.

\section{METHOD AND ANALYSIS}

To accomplish this, a web based content analysis was used to reveal the characteristics and dimensions of the aggregate level curricula of US based aviation programs. Harvesting content from institutional descriptions of courses and programs has proven to be an effective means of providing strong research results (An, 2007). Doing so provides meaningful insight into what jobs, skills, professions, and industries the US based aviation management curriculum is preparing our students for upon graduation. 56 collegiate baccalaureate aviation programs spread across five distinctly different types of colleges were examined (UAA, 2007). The sample was generated based on the overall list of all aviation related programs (graduate, 4-year, 2-year, and technical) as identified by UAA. As shown in table 1, while the course content is similar, the courses are taught in various colleges within the university such as engineering, business, education, or liberal arts. How did this variation occur and does it impact the discipline? Does the location of the baccalaureate aviation program within the university environment impact whether the goal is to educate professionals for the management of engineering, science and technology, business, or education? Alternatively, do the curricula educate aviation students based upon a somewhat consistent curriculum model that simply "ended up" in various schools or is the variety of course work vastly different depending on location within the university?

Table 1: Benchmark Collegiate Four-Year Programs

\begin{tabular}{|l|l|}
\hline College of Engineering (4) & Hampton, Ohio, San Jose, Tennessee State \\
\hline College level Unit & Daniel Webster, Dowling, Embry, Everglades, Florida \\
& Institute of Technology, Florida Memorial, Middle \\
Georgia, Rocky Mountain, Tarlington State, U of Illinois \\
Urbana-Champaign, Minnesota Crookston, Western \\
Michigan
\end{tabular}

Source: UAA, and individual websites

As shown in table 2, the colleges and universities included in this study offer a total of 174 aviation-related four-year degree programs. The purpose of our research is to better understand the underlying content of these programs. As a result, this is a timely research program aimed at better understanding the wide disparity of aviation management programs as the academy begins to consider new AABI outcomes-based accreditation criteria.

This investigation uses content analysis to define and generate a typology of aviation curriculum models and to determine the core content and intended outcomes at an aggregate level. Research on communication has shown content analysis to be an effective means to 
generate understanding (Kassarjian, 1977; Spears, 2001; Stafford, Spears, \& Chung-kue, 2003). Content analysis effectively examines intended messages based upon frequency of discrete written content provided by a person or organization (An, 2007; Kassarjian, 1977; Spears, 2001). Content analysis provides a way of understanding an entity's "apparent" intent with respect to an apparent "audience" (Kassarjian, 1977) therefore content analysis was considered to be the appropriate method considering the goals of our research.

Table 2: Aviation Management (Business, or Technology) Related Four Year Degrees Key Word in the Degree

\begin{tabular}{|cl|l|}
\hline 1. & Management & 46 \\
\hline 2. & Flight & 40 \\
\hline 3. & Science & 27 \\
\hline 4. & Technology & 13 \\
\hline 5. & Maintenance & 12 \\
\hline 6. & Administration & 9 \\
\hline 7. & Air Traffic Control & 6 \\
\hline 8. & Aeronautics & 4 \\
\hline 9. & Operations & 3 \\
\hline 10. & Logistics & 2 \\
\hline 11. & Security & 2 \\
\hline 12. & Agricultural & 1 \\
\hline 13. & Aviation education & 2 \\
\hline 14. & Aviation Engineering & 1 \\
\hline 15. & Business Aviation & 1 \\
\hline 16. & Corporate and general & 1 \\
\hline & aviation & \\
\hline 17. & Homeland Security & 1 \\
\hline 18. & Human factors & 1 \\
\hline Total & & 174 \\
\hline
\end{tabular}

\section{SAMPLING AND UNIT OF ANALYSIS}

The sample for this investigation was chosen from the baccalaureate collegiate aviation programs of the University Aviation Association (UAA). Information on each aviation program was gathered from their respective program website. Both course descriptions associated with each program and the text posted on the website describing each program was used in the analysis phase of the research method. Increasingly websites are used by organizations to project strategic content toward intended customers (An, 2007). The use of web-based corporate messages provided an effective source of data to obtain content for later aggregation and analysis. Using a webbased method overcomes the notorious "low response rate" associated with survey research (Dillman, 2000); we generated a " $100 \%$ response" from the sampled firms' websites. Websites have been used in similar content based analytical investigations of intended value proposition with great success (Randall \& Defee, 2008).

The data collection and investigation process consisted of a multi-step approach to data reduction. Our ability to "count" search words within each category allows specific, weighted, curricula elements to be placed within a broad taxonomy. For instance "global air transportation" was identified as a word element within the business process category at the industry level. Yet the relatively sparse usage of the term suggests the element is not a robust and frequent dimension when measured across curricula (Glaser \& Strauss, 1967).

In another example descriptive of the methodology the term "airframe" was found 89 times. There were also numerous related descriptive words such as wing, air foil, engine, etc. These words represent a common category of nouns that deal with a technical understanding of assets central to the aviation industry. As a result, these words are placed in a Technical Understanding Category. In a final example there were also several descriptive words dealing with airlines, air-cargo, air taxi, etc., that appeared to be more focused on a broader understanding of Business Processes.

\section{DATA PREPARATION}

Each of these program specific text files were then individually imported into a qualitative software program known as Max Qualitative Data Analysis (MAXQDA). The investigation focused on the use of the quantitative tools to support data reduction and categorization of aviation program curricula (Lewins \& Silver, 2006). The initial content count generated 9,934 distinct words in 56 texts. These texts are based upon the individual program's website. The software tool was then used in an iterative process to reduce the data to 
a final key word list of 1,800 descriptive words and their frequency.

Two researchers independently began the coding of key terms into sub-categories. During this process each of the key terms were linked back to their original website content in order to affirm contextual understanding. These steps allowed us to evaluate the aviation related intent of each term. The initial context-linked catalog of key terms was culled, and aggregated, to include only words that contained aviation, education, technological, business or supply chain specific meaning. This resulted in a refined "short list" of 100 words. These words fell along two broad categories based upon context and frequency. These two broad categories of constructs emerged that were associated with the 56 baccalaureate aviation curricula models evaluated.

\section{CATEGORIZATION AND DIMENSION}

The software tool was then used to index each of the 100 key words so that a link back to the original text was constructed. The researchers then independently generated categories associated with these key descriptive words. This step resulted in broad content categories associated with the words and their frequency. These results were harmonized based upon discussion, agreement and common understanding. The result was categories of aggregated content with frequency based dimensions (Charmaz, 2006). For instance, "process" arose as a highly weighted variable. Analysis revealed that "process" exhibited a strong dimension in the content analysis. At one edge "process" was associated with operational or flying processes while at the other edge, "process" was associated with business or management processes.

Figure 1 provides an aggregate level curricula map that gives a spatial representation of the content analysis. The research indicates the two broad categories with dimensions associated with collegiate aviation programs. The $\mathrm{X}$ axis deals with the intellectual objectives of the program; how the students are being trained or educated to think and act. The second broad category or dimension is the assimilation of knowledge; the content of knowledge intended to be absorbed by the student.

The "intellectual objective" category and dimension is aimed at affecting the manner and ability with which the students think and solve problems. The right end of the $\mathrm{X}$ axis deals with the ability of the student to perform operational level activities that require procedural skill and understanding. This tends towards such activities as flying, tower operations, dispatch, etc. The left side of the X axis deals with the ability of the students to perform business processes such as management, administration, cost benefit analysis, decision making, etc. The assimilation of knowledge category and dimension deals with the type of knowledge and to what affect that knowledge is intended. Over this is laid an oval which represents the preponderance of weight for the aggregate level curriculum. That is, while individual courses and programs may well fall outside the oval, at the aggregate, this is the area where the baccalaureate programs educate and train their students. This oval is based upon a subjective yet empirically informed assessment of categories, word elements, and word weights.

This research provides a glimpse into the core categories of knowledge and learning suggested by the aggregate curricula, the weight programs put on these variables, where the preponderance of programs currently reside along each axis and dimension, and those outliers. Such taxonomy moves closer to identifying the intersections of flight skill, knowledge, course content, and cognitive development. Our investigation uncovers the characteristics and dimensions of the aggregate level curricula of US based aviation programs. This investigation identifies a set of benchmarks that, when interpreted in light of an institution's mission and culture, can aid in optimizing experiences for students. The second goal, to help all aviation management programs to lay legitimate claim to the status of "an exceptional program" serving industry needs, is achieved. 


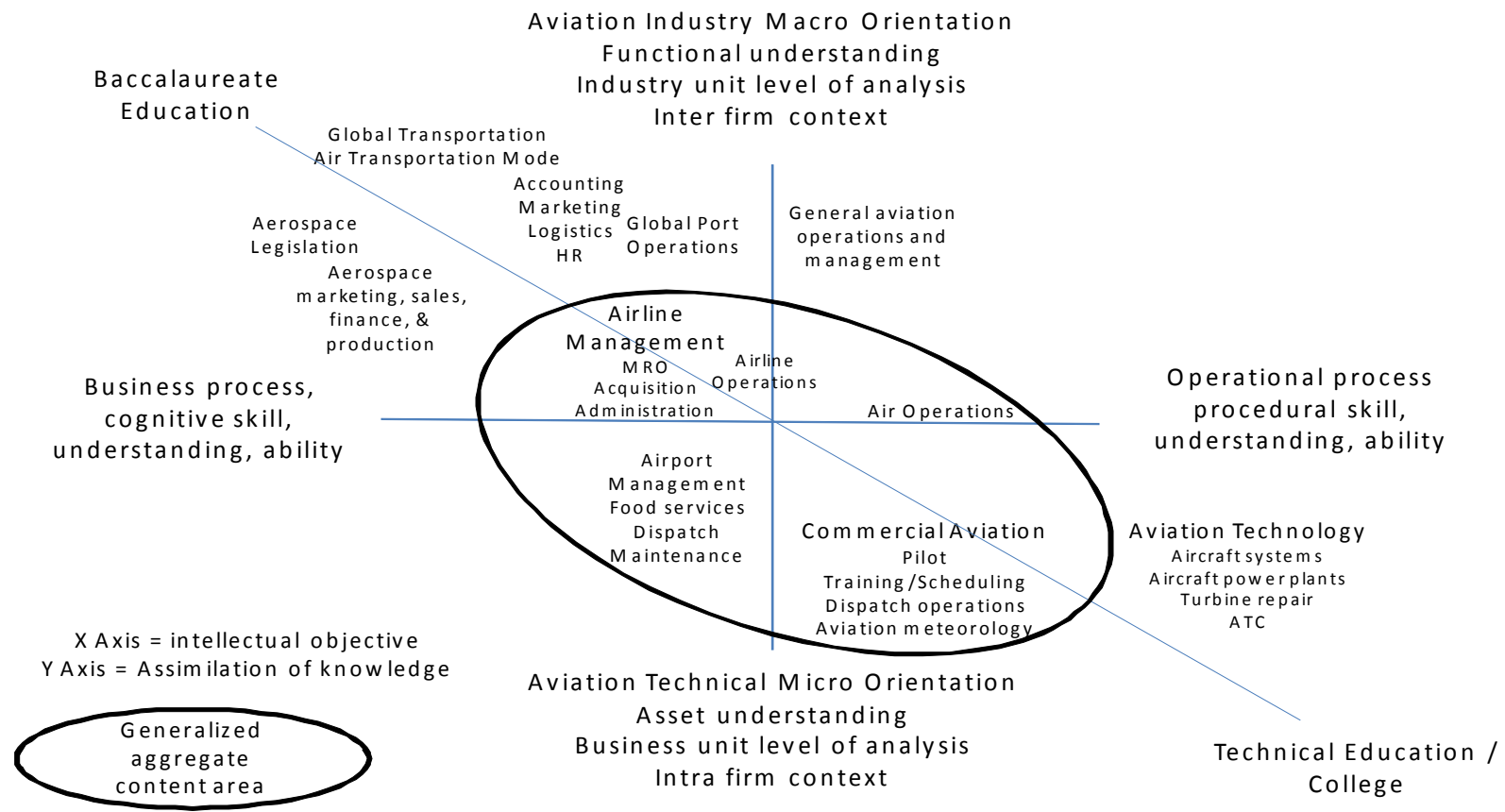

Figure 1: Taxonomy of Collegiate Aviation Curricula

\section{A Proposed Aviation Management Curriculum Model}

"Benchmarking" facilitates and enhances active engagement of key players and stakeholders (Haworth \& Conrad, 1997). The proposed framework provides program dimension to support such benchmarking efforts in light of a shifting focus in aviation curricula. The results of our research provide a taxonomy model (See Figures 1 and 2) from which individual programs can judge their content and positioning.

Administrators depend on benchmarks to compare their institution's program quality, content and position with that of other peer institutions. In addition, administrators also use benchmarks to support a program in developing a distinctive mission. This is particularly important to collegiate aviation programs where oftentimes each program is perceived as an anomaly among academic colleges' alignment of traditional disciplines. The benchmarking information is also valuable for students since the information enables them to make well informed choices when considering matriculation in a program.

The three assessment areas for aviation curriculum are based on: (1) breadth of curriculum, (2) science foundation, and (3) curriculum structure. These proposed evaluation criteria characteristics range from marginal to exceptional. It is our hope that using the taxonomy of the aggregate level baseline curriculum provided here, our discipline can enhance the evaluative process of collegiate aviation education programs.

\section{Implications: Characteristics of an "Exceptional" Aviation Management Program?}

Table 3 provides a benchmarking framework based upon this analysis. In the recommended benchmarks, we employ the term exceptional to refer to the characteristics of an aviation management program that makes exceptional contributions to how well students learn about and are prepared for the demands of the broad elements of the aviation industry. We designate the next level of program function as effective which represents making an aboveaverage, appropriate and positive contribution to student learning. An average benchmark meets, but does not exceed an adequate contribution. In contrast, characteristics that are marginal are counterproductive to an overall collegiate educational mission aimed at preparation for the aviation industry. 
Table 3: Recommended Benchmarks for Assessing Aviation Management Programs

\begin{tabular}{|c|c|c|c|c|}
\hline $\begin{array}{l}\text { Achievement } \\
\text { Level: }\end{array}$ & Marginal & Adequate & Effective & Exceptional \\
\hline Breadth of curriculum & $\begin{array}{l}\text { Limited focus } \\
\text { based on tradition } \\
\text { \& faculty interests }\end{array}$ & $\begin{array}{l}\text { Limited breadth } \\
\text { beyond faculty } \\
\text { interests }\end{array}$ & $\begin{array}{l}\text { Broad curriculum } \\
\text { reflecting scope } \\
\text { of profession }\end{array}$ & $\begin{array}{l}\text { Broad } \\
\text { curriculum: } \\
\text { students } \\
\text { evaluating \& } \\
\text { integrating facets } \\
\text { of aviation } \\
\text { management }\end{array}$ \\
\hline Science foundation & $\begin{array}{l}\text { Limited scientific } \\
\text { orientation } \\
\text { dependent on } \\
\text { individual faculty } \\
\text { member(s) }\end{array}$ & $\begin{array}{l}\text { Non-systematic } \\
\text { science } \\
\text { orientation } \\
\text { encouraged by } \\
\text { faculty } \\
\text { administration }\end{array}$ & $\begin{array}{l}\text { Curriculum built } \\
\text { on scientific } \\
\text { foundation } \\
\text { echoed } \\
\text { throughout the } \\
\text { curriculum }\end{array}$ & $\begin{array}{l}\text { Science-based } \\
\text { curriculum } \\
\text { requiring } \\
\text { students' } \\
\text { demonstration of } \\
\text { scientific method }\end{array}$ \\
\hline Curriculum structure & $\begin{array}{l}\text { no specific } \\
\text { structure; } \\
\text { determined solely } \\
\text { by student interests }\end{array}$ & $\begin{array}{l}\text { Core } \\
\text { requirements but } \\
\text { no attention to } \\
\text { sequence \& } \\
\text { development of } \\
\text { skills }\end{array}$ & $\begin{array}{l}\text { Sequences a } \\
\text { broad base of core } \\
\text { requirements; } \\
\text { may entail an } \\
\text { integrating } \\
\text { capstone } \\
\text { experience }\end{array}$ & $\begin{array}{l}\text { Sequenced to } \\
\text { achieve growing } \\
\text { student cognition } \\
\text { of the discipline } \\
\& \text { requisite } \\
\text { managerial skills } \\
\text { for aviation } \\
\text { industry }\end{array}$ \\
\hline
\end{tabular}

Source: Adapted from Dunn et all (2007, p. 665)

These benchmarks should aid in highlighting problems and may help to redirect a program's efforts toward renewal and revitalization of purpose and pedagogy. Such evaluation may point to the need for a critical reassessment of a program's educational goals if the program's advocates so desire. The labels are appropriate for formative assessment in contrast to summative assessment, and provide a multidimensional method for evaluating a department's progress toward mastery of the quality benchmarks aimed towards the emerging demands of the aviation industry. Thus, average and marginal should be viewed as relative labels that aid self critical program evolution.

In some cases, the presence of marginal areas might indicate an intentional program focus on a narrower technical / skill focus. In other cases such evaluation may indicate a lack of well-defined goals within a program based upon historical path dependencies (Bettis \& SzeSze, 2003; Hunt \& Morgan, 1996). Marginal results may indicate a lack of overall program integration. Such lack of a strategic path and goals may lead to neglect of responsibilities, lack of faculty and student engagement, severe resource constraints, or even collegial strife (Avolio \& Bass, 1988; Chemers, 1997; House, 1996).

\section{CONCLUSIONS}

We have provided a foundation for codification of aviation programs. As discussed earlier there are 56 institutions with aviationrelated four-year degrees. These programs reside in five distinct academic colleges. In total, we identified 174 degree programs that appear to involve 18 distinct baccalaureate 
degrees. In this initial investigation the development of "category" was done by consensus of the aviation researchers conducting the study. The analysis brought forth two broad, multi-dimensional, categories. Our method generated a taxonomic and dimensional analysis with respect to collegiate aviation curriculum.

Based upon our research, our recent contacts with industry, and indications from AABI, we find that there appears to be a growing need for industry based business process educational objectives to be added to aviation management curriculum models. This can be viewed as good news. Aviation has grown beyond its role as a niche program to become more of a central pillar in a timedefinite, increasingly global, economy. However the implication is that this economy requires a collegiate aviation student with a view well outside of the cockpit, one ready to employ business based skills to analyze, decide, and act with robust business based acumen.

The aviation discipline is ascending as an important management element in the global economy. For some this is a very exciting time. For others this is cause for concern as in their view, the operational roots may be becoming obscured. There is a stark reality that as we add industry focused courses, other more classical courses might be curtailed or dropped. The question then becomes how, and to what extent, does a program integrate operational content into industry decision making focused courses.

In essence we have a divergence, possibly even a crisis in the aviation curriculum and discipline. Why are there so many programs across so many different colleges? Why is there such disparity in the content of various aviation related majors? It appears that the discipline is struggling to define its core elements and intent.

For those academics and researchers who have moved from the cockpit to the school house, aviation management will always have the essence of flight, the smell of jet fuel, and the allure of a 30,000 foot view. Aviation Management from that perspective appears to be Aviation Operations. For that breed, the collegiate aviation paradigm is centered on the flight aspect of aviation. "Core" content is logically focused on aviation operations such as Air Traffic Control, Meteorology, Airport
Operations, Maintenance Operations, Cockpit Resource Management, and Safety. In this, the historical perspective, Aviation Management is Aviation Operations. Classes and research therefore correspond to those areas.

Yet there are others looking closely at the aviation industry from a different perspective. These academicians see a strong industry basis for the discipline. While they too have responded to the allure of aviation whose essence is flight, their backgrounds in logistics, supply chain management, international business, manufacturing, retail, and operations bring into focus a different paradigm of aviation management. They see aviation as the time and distance compressing industry. They see a massive economic sector with increasing importance as consumers demand products and services that are better, faster, and cheaper (Lee, 2004). These industry focused academicians see curriculum content weighted toward the ability to optimize routes as a means of optimizing total cost (LeKashman \& Stolle, 1965). These academicians consider a systems dynamic which integrates rail, sea, truck and air into a sophisticated transportation system that effectively serves today's supply chain networks. They find air to be the time and place champion in the intermodal transportation network. For these academicians, meteorology provides content to teach the impact of natural and manmade disaster as a disruption of a global supply chain.

We reflect back on Phillips' statement that "flight and aviation management programs are linked much like conjoined-twins. The degree to which the programs are linked may put too much emphasis on the technical aspects of aviation at the expense of the management aspects." (Phillips, 2004) Can they coexist? Is there a crisis in the Kuhnean (1996) sense? Is Aviation Management an operational discipline oriented toward managing sortie generation? Or is the substantive content of Aviation management aimed at managing the aviation industry? Can both be taught as part of one major? Should they? Are these two different degrees or disciplines? One Flight Operations Management, the other Air Transportation Management? Considering the impending evolution in AABI accreditation criteria and 
incongruence in orientation as dictated by the results of our research, it might be time we consider how we might avert a crisis or take advantage of a tremendous opportunity in the global economy.

Can those who view the aviation industry from the cockpit peacefully coexist with those who view the aviation industry as a business sector aimed at providing expedited time and place utility? We believe so. We believe our explanation may give mutual understanding to these, at times competing, perspectives. With understanding perhaps comes integration, synthesis, and evolution. Such "crisis" in a discipline may actually be an encouraging growing pain leading to a tremendous opportunity for the discipline. Similar discipline "crises" have occurred in other academic disciplines such as marketing (Hunt, 1992; Kavanagh, 1994), information systems (Burrell \& Morgan, 1979), Operations Management (Meredith et al., 1989) and supply chain management (Novack, Rinehart, \& Wells, 1992; Stock, 1990) with most believing the end result to be evolution and discipline enhancement. The challenge to the aviation management academy is to search out those common elements that uniquely identify aviation management as a discipline. Our analysis provides a schema from which to begin this process. The proposed taxonomy will help a program examine its relative position and its offerings. Coupled with a viable model to benchmark quality, we provide a program's faculty and administration an initial tool designed to measure effectiveness in serving aviation industry needs. At the aggregate, once there is understanding of the common curricular elements which reflect the industry's needs, aviation management will advance toward a distinct and robust discipline. 


\section{REFERENCES}

Adrangi, B., Chow, G., \& Raffiee, K. (1997). Airline Deregulation, Safety, and Profitability in the U.S. Transportation Journal, 36(4), 44.

An, D. (2007). Advertising Visuals in Global Brands' Local Websites: a Six-Country Comparison. International Journal of Advertising, 26(3), 303-332.

Avolio, B. J., \& Bass, B. M. (1988). Transformational leadership, charisma, and beyond. Lexington, MA: DC Heath.

Bettis, R. A., \& Sze-Sze, W. (2003). Dominant Logic, Knowledge Creation, and Managerial Choice. Blackwell handbook of organizational learning \& knowledge management, 343-355.

Burrell, G., \& Morgan, G. (1979). Sociological paradigms and organisational analysis. Hants, England: Ashgate Publishing Company.

Charmaz, K. (2006). Constructing grounded theory: A practical guide through qualitative analysis. Thousand Oaks, CA: Sage Publications, Inc.

Chemers, M. M. (1997). An integrative theory of leadership. Mahwah, New Jersey: Lawrence Erlbaum Associates.

Clark, J. M. (2006). The Face of Collegiate Aviation: Factors impacting Self-Selection of Collegiate Aviation Programs. Collegiate Aviation Review, 24(1).

Dillman, D. A. (2000). Mall and internet surveys (Second ed.). New York: John Wiley and Sons.

Dunn, D. S., Mehrotra, C. M., \& Halonen, J. S. (2007). Quality Benchmarks in Undergraduate Psychology Programs. American Psychologist, 62(7), 650-670.

Engler, J. (2007). Transportation Infrastructure Crucial to Manufacturing. Plant Engineering, 61(11), 5050 .

Erickson, J. (2006). ALL-CARGO AIRLINES. Aviation Week \& Space Technology, 164(3), 399-401.

Fabey, M. (2007). Separate Flights Paths For U.S. shippers and forwarders. Traffic World, 271(44), 1821.

Fairbairn, G. R. (1987). Development of aviation management coursework. Paper presented at the 1987 Proceedings of the University Aviation Association Fall Education Conference, October 1987.

Flint, P. (2007). Balancing Act. Air Transport World, 44(11), 47-54.

Glaser, B. G., \& Strauss, A. L. (1967). The discovery of grounded theory. Chicago, IL: Aldine Transaction.

Golicic, S. L., Bobbitt, L. M., Frankel, R., \& Clinton, S. R. (2004). And Who Will Teach Them? An Investigation of the Logistics PhD Market. Journal of Education for Business, 80(1), 47.

House, R. J. (1996). Path-Goal Theory of Leadership: Lessons, Legacy, and a Reformulated Theory. Leadership Quarterly, 7(3), 323-352.

Hunt, S. D. (1992). For Reason and Realism in Marketing. Journal of Marketing, 56(2), 89-102.

Hunt, S. D., \& Morgan, R. M. (1996). The Resource-Advantage Theory of Competition: Dynamics, Path Dependencies, and Evolutionary Dimensions. Journal of Marketing, 60(4), 107-114.

Kassarjian, H. H. (1977). Content Analysis in Consumer Research. Journal of Consumer Research, 4(1), 8-18.

Kavanagh, D. (1994). Hunt versus Anderson: Round 16. European Journal of Marketing, 28(3), 26-41. 
Kuhn, T. S. (1996). The structure of scientific revolutions (3rd ed.). Chicago, IL: The University of Chicago Press.

Lee, H. L. (2004). The Triple A Supply Chain. Harvard Business Review, 82(10), 102-112.

LeKashman, R., \& Stolle, J. F. (1965). The Total Cost Approach to Distribution. Business Horizons, 8(4), 33.

Lewins, A., \& Silver, C. (2006). Choosing a CAQDAS package: A working paper. Surrey, UK: Surrey University Computer Assisted Qualitative Data Analysis Networking Project o. Document Number)

Meredith, J. R., Raturi, A., Amoako-Gyampah, K., \& Kaplan, B. (1989). Alternative Research Paradigms. Journal of Operations Management, 8(4), 297-326.

Novack, R. A., Rinehart, L. M., \& Wells, M. V. (1992). Rethinking Concept Foundations in Logistics Management. Journal of Business Logistics, 13(2), 233.

Phillips, E. D. (2004). A Critique of Aviation Management Programs. Collegiate Aviation Review, 22(1).

Phillips, E. D., Ruiz, J. R., \& Mehta, H. (2006). Industry Members Evaluate the Strengths and Weaknesses of Aviation Management Graduates. Collegiate Aviation Review, 24(1).

Quilty, S. M. (2004). Airport Management Program and Curriculum Issues at 2 and 4-year Colleges and Universities. Collegiate Aviation Review, 22(1).

R.W. Kaps, L. L. W. (1995). Educational requirements for a career in airport management: an industry perspective. Journal of Studies in Technical Careers, $X V(3)$.

Randall, W. S., \& Defee, C. C. (2008). Exploring 3PL Value Propositions. Journal of Transportation Management, Fourthcoming(Fall 2008).

Spears, N. (2001). Time Pressure and Information in Sales Promotion Strategy: Conceptual Framework and Content Analysis. Journal of Advertising, 30(1), 67-76.

Stafford, M. R., Spears, N. E., \& Chung-kue, H. (2003). Celebrity Images in Magazine Advertisements: An Application of the Visual Rhetoric Model. Journal of Current Issues \& Research in Advertising, 25(2), 13-20.

Stock, J. R. (1990). Logistics Thought and Practice: A Perspective. International Journal of Physical Distribution \& Logistics Management, 20(1), 3.

Taylor, J. C., \& Jackson, G. C. (2000). Conflict, Power, and Evolution in the Intermodal Transportation Industry's Channel of Distribution. Transportation Journal, 39(3), 5.

UAA. (2007). University Aviation Association, University Aviation Membership List, 2007. Retrieved January 10，2008, from http://www.uaa.aero/sitefiles/uaa/resourcebin/CurrentMbrList_Inst.pdf] (Publication.:

Wergin, J. F. (2003). Departments that work: Building and sustaining cultures of excellence in academic programs. Bolton, MA: Anker. 